\title{
New era for the JEGYS
}

\author{
Hasan Said Tortop ${ }^{1}$ \\ Association for Young Scientists and Talent Education, Turkey
}

\begin{abstract}
JEGYS has aimed to combine the gifted education with the science education since first issue. JEGYS continued to develop by creating a new academic field. It brought the concept of "advanced science education" to the academic literature. Now, it presents a series of innovations and developments to its writers and readers in order to keep up with the change in every field in the world. It takes importance the first steps in publishing by updating the principles of strict academic review, broad country participation, visibility and transparency in its editorial policy. In this article, these topics are discussed in details and with examples.
\end{abstract}

Keywords: Academic social media, editorial, JEGYS, improvement, transparency, visibility

\section{Dear Authors, Readers, Reviewers, Editors}

JEGYS was established in 2013 with the idea that training scientists can only be possible with the education of gifted individuals. Science education policies need to be combined with the education policies of gifted children. JEGYS started its publication with the idea that "Science education should be given to everyone, but the theories and practices of gifted education should be used to train the young scientists".

Throughout our publication life, we have passed through difficult times. We made an effort to publish the articles of authors in developed countries where gifted and advanced science education. With the support of valuable academicians in our editorial board, we made JEGYS an international journal. It makes us very happy that JEGYS is one of the few journals in the world that publishes on the education of gifted. I would like to thank our editorial board members and JEGYS family for their efforts in this process. Prof. Dr. Albert Ziegler, Prof. Dr. Hanna David, Prof. Dr. Franz Mönks (deceased), Prof. Dr. Gillian Roehrig, Prof. Dr. Andrew Johnson, Dr. Milan Kubiatko, Dr. Abdurahman, Prof.Dr. Kirsi Tirri, Dr. Alberto Rocha, Prof.Dr. Vilma Vialle, Dr. Suhail Alzoubi, Dr. Abu Yazid Abu Bakar, Dr. Pakkapong Poungsuk always gave their support.

In the new period of JEGYS, we continue to monitor and increase the readability and visibility of our academic journal in the world. For this, we use a program called Flag Counter. In each publication period, we will evaluate country-based increases with our editorial board. As seen in Figure 1, our website was visited from 91 countries in a short period of 15 days. This is a great success for JEGYS. JEGYS, which publishes articles in a partially specific field, is followed by academics from many countries of the world.

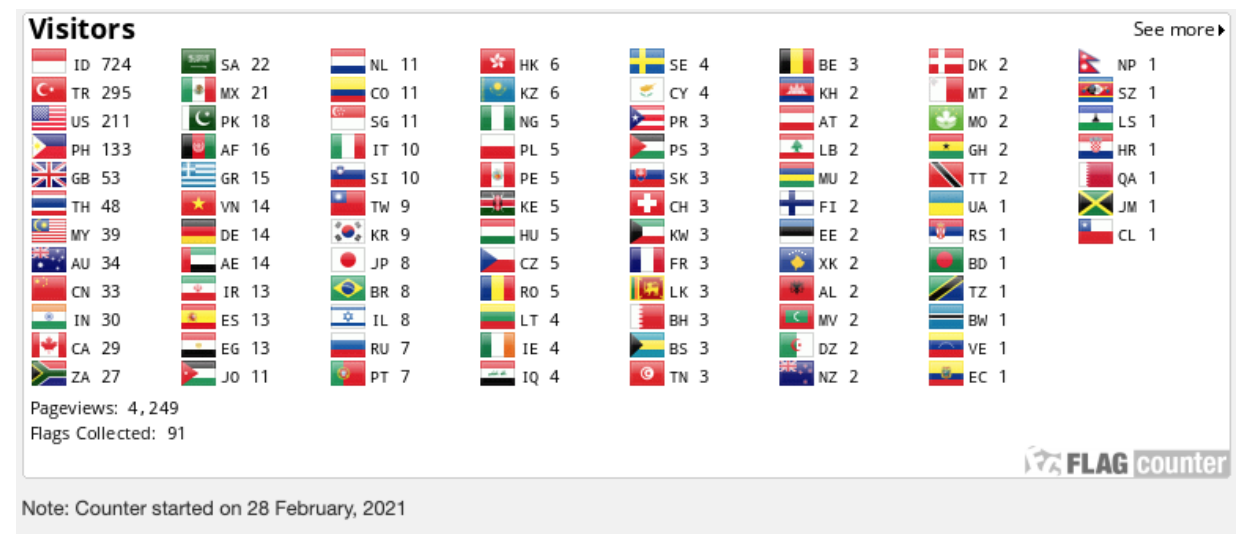

\section{Figure 1.}


Flag Counter Program Data for Worldwide Monitoring of JEGYS (13 March, 2021; time 12:32 at Turkey)

The issues we will take importance to in the new period are as follows; publishing research on advanced science education for gifted, talented and highly achiever students, submitting reports showing the average duration of referee evaluation, increasing book reviews and interviews, announcing special issues, reaching more readers and academics. Our evaluation process continues in the ERIC index, which is the most important index in the field of education in the world. We continue to make improvements in subjects such as increasing the country distribution of authors, improving referee processes, and increasing the quality of English grammar of articles.

Table 1.

March 2021 Issue Article Review Process Data

\begin{tabular}{lcccc}
\hline Articles ID & Reviewers number & $\begin{array}{c}\text { Review Time } \\
\text { (Average) }\end{array}$ & Contributions to Field & Countries \\
\hline $\mathbf{8 3 7 2 2 7}$ & 2 & 60 days & Project compettions & Turkey \\
$\mathbf{8 2 1 7 0 0}$ & 2 & 120 days & Science camp & Malaysia \\
$\mathbf{7 9 2 2 0 3}$ & 2 & 150 days & Sport talent & Slovenia \\
$\mathbf{8 6 4 1 0 4}$ & 2 & 60 days & Education & Poland \\
& & & policy/system & \\
$\mathbf{7 5 4 1 0 4}$ & 2 & 240 days & Differentiation & Turkey \\
$\mathbf{8 1 7 2 7 7}$ & 3 & 120 days & Thinking skills & Indonesia \\
$\mathbf{8 6 4 3 9 9}$ & 3 & 60 days & Creativity & Bahrain \\
\hline Total & At least 2 reviewers & 116 days & Gifted education & 6 different \\
& & & & contries \\
\hline
\end{tabular}

As seen in Table 1, articles from 6 different countries were published in the March 2021 issue, with at least 2 referee evaluation and review processes that lasted an average of 116 days, all of which would contribute to the topics in gifted education. Thanks to our referees in this review process. Academicians who want to work as referees can send an e-mail to editorjegys@gmail.com. The late referee turnaround times and the response rate of the appointed referees are $50 \%$. The assignment of referees who can make meticulous and high-quality reviews in about 1 month is one of the issues we will focus on the most in this new period.

JEGYS is currently working with 7 editors. Again, we make our announcement to the academicians who want to work as editors by adding their CV to the e-mail address.

We made our special issue announcement. Special Issue Call (STEM for Gifted) Last date to submission: October 15, 2021. STEM education has proposed a unifying discipline approach as of its first appearance. However, besides the interdisciplinary approach, a metadisciplinary approach is also recommended in the education of gifted students. The meta-disciplinary approach is not yet included in STEM education. However, the thesis that STEM education is aimed at general and normal students has not been proven yet. Our opinion is that STEM education is for gifted students. To support this, it is to publish "STEM for Gifted" as a special issue in 2021. We are calling authors studying in this field for articles for this special issue, the relationship between birth order and creativity in gifted children was investigated.

In the new era of JEGYS, we provide readers with easy access to the Academic Social Media for writers. In addition, we enable readers to see the author's abstract with the video he reads. One of our authors in this issue did this as an example. Based on feedback, we will design the next issue of articles in this format. JEGYS will continue to be a pioneer in academic publishing with innovations that provide the social visibility of authors. 


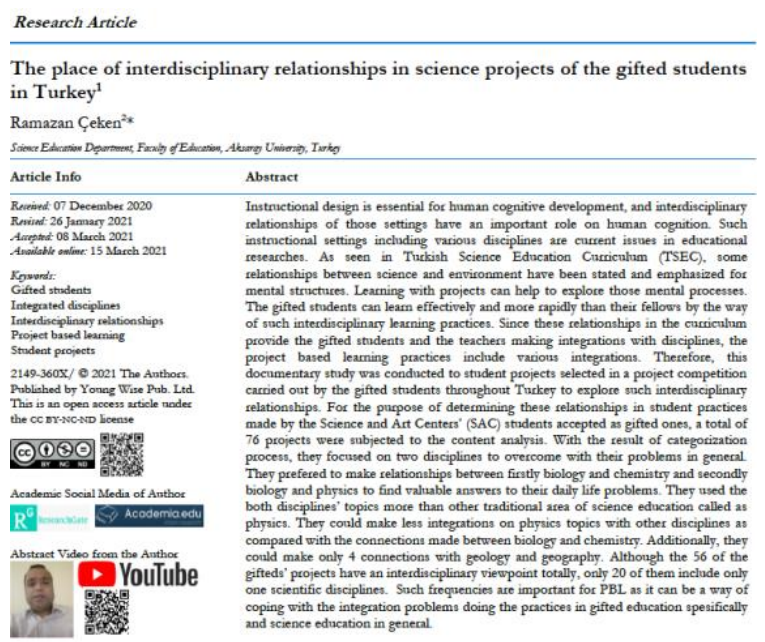

Figure 1.

Author's Academic Social Media Plugin on the First Page of the Article

In March 2021 issue; first article; the projects prepared by gifted students in competitions have been examined in terms of interdisciplinarity, second article; the STEM skills development aspect of the science camp for preschool students was examined, and this research is a very valuable research in terms of examining science camps in preschool period, fourth article; an examination of football talent at primary level has been conducted in Slovenia, fifth article; the problems of the Polish education system during the pandemic period and the situations of gifted children in this process were examined, sixth article; the effect of using differentiation in the education of gifted children on the development of their creativity was examined, seventh article; learning styles and motivation in gifted children have been investigated.

In this issue, it is seen that all seven articles are research articles. We state that we are honored to publish articles guiding gifted students and advanced science education. We thank you for your contribution and support to JEGYS, which is the most followed platform by academics, policy makers and educators study in gifted and advanced science education.

Best regards

Dr. Hasan Said Tortop

Editor-in-Chief of the JEGYS 